\title{
Planificación de la inmediatez. Incidencia de la infraestructura urbana en el nivel de conservación histórica: el caso de “Ambiente Urbano Monumental 15 de Junio", Huancayo, Perú, 1970-2019
}

\begin{abstract}
Short term planning. Incidence of urban infrastructure on the urban heritage: The case of the "Ambiente Urbano
\end{abstract} \\ Monumental 15 de Junio", Huancayo, Perú, 1970-2019
}

\section{Gonzalo Peña Zamalloa}

Facultad de Ingeniería, Universidad Continental, Huancayo, Perú. gzamalloa@outlook.com

\section{Resumen}

Las áreas urbanas históricas de las ciudades representan una parte importante de la imagen urbana al ser parte de legado inicial de la ciudad; sin embargo, muchas de éstas áreas se encuentran envejecidas perdiendo su valor histórico. Esta investigación analiza las modificaciones en la infraestructura urbana, bajo un enfoque caminable, y su incidencia en el estado de conservación del caso del Ambiente Urbano Monumental 15 de Junio, de la ciudad de Huancayo, Perú. Se reconstruye los fenómenos urbanos a través de la revisión documental y entrevistas semiestructuradas a 12 personas con residencia semipermanente en el área por alrededor de 50 años. Se utiliza un modelo de regresión lineal múltiple jerárquica para evaluar la capacidad de predictibilidad del estado de conservación a través de la medición de la infraestructura urbana. Se identificó que el tamaño de la acera, la facilidad de cruce, el uso nocturno del espacio público y el uso de edificación contribuyeron significativamente en la predictibilidad del nivel de conservación del ambiente en estudio.

Palabras clave: ambiente histórico urbano, caminabilidad, infraestructura urbana, patrimonio cultural, planificación urbana.

\begin{abstract}
Urban heritage areas in the city represent an important part of urban image because they constitute some of the key built areas in the city; however, many of them are very damaged losing part of their historical value. The research analyzes the changes in the urban infrastructure, under a walkability focus, and their incidence on the preservation level for the case of the Heritage Urban Environment of 15 de Junio in the city of Huancayo in Peru. The urban phenomena are presented based on documentary review and semi-structured interviews to 12 people with semi-permanent residence in the area for about 50 years. Finally, a hierarchical multiple linear regression model is used to evaluate la predictability capability of the preservation state based on the urban infrastructure. It was recognized that walkaway size, cross easiness, night use of public space and building use contributed significantly to the predictability of preservation levels in the area of study.
\end{abstract}

Keywords: cultural heritage, historical urban environment, urban infrastructure, urban planning, walkability.

Documento recibido el 19 de julio de 2019 y aceptado el 11 de diciembre de 2019.

Cómo citar: Peña Zamalloa, G. (2019). Planificación de la inmediatez. Incidencia de la infraestructura urbana en el nivel de conservación histórica: el caso de “Ambiente Urbano Monumental 15 de Junio”, Huancayo, Perú, 1970-2019. Revista de Urbanismo, 41, 1-22. https://doi.org/10.5354/0717-5051.2019.53901 


\section{Introducción}

La ciudad en el mundo contemporáneo requiere ser atractiva a través de los paisajes que se generan en la misma por la actuación de sus propios ciudadanos y la imagen que desea proyectar (Ortiz de Villajos Carrera, 2015). La ciudad tiene una imagen interna y externa. Por ello, la planificación urbana debe contribuir al desarrollo de una imagen positiva. El presente trabajo explora la la preservación de la imagen histórica de una zona central de Huancayo, una ciudad peruana emergente y con periodos de rápido crecimiento, especialmente en la década de 1990 y 2010 en adelante

En el contexto urbano latinoamericano, Mertins (2018) ve de forma positiva la inclusión de los centros históricos en planes territoriales de las ciudades. El patrimonio cultural tiene un rol importante para la imagen de la ciudad, para el residente y el visitante. Para Ortiz de Villajos Carrera (2015), la ciudad renueva su patrimonio cultural con el objetivo de obtener un beneficio y que se puede expresar en un cambio de uso del inmueble y es reinventado bajo una visión mas contemporánea. Los recursos para vincular la regeneración urbana con el presente, según Hwang(2014), involucran a los eventos históricos, el valor del paisaje y las memorias de la ciudad.

Esta aproximación a la gestión del patrimonio se distingue también en el estudio de Sánchez, Teutli y Maximiliano (2016), quienes sugieren evaluar los elementos culturales materiales e inmateriales dentro de los procesos de planificación urbana. Se debe considerar que elementos de los espacios públicos tienen un rol identificable, entre estos pueden estar los materiales, texturas, circulación peatonal dentro de los espacios públicos. Su correcta identificación puede servir como medio para integrar efectivamente espacios públicos nuevos e históricos en los proyectos urbanos.

Sánchez, Teutli y Maximiliano (2016) indican que en algunos casos latinoamericanos, los centros históricos delimitados han sido apropiadamente intervenidos, mientras que en otros han tenido poco éxito. Las razones de ello son diversas y se han volcado muchas opiniones al respecto. En general se asocia la baja comprensión de la dinámica urbana a las malas decisiones de planificación. Almandoz (2006) sugiere que el fracaso de los planes urbanos bajo lineamientos modernistas funcionalistas tuvieron un efecto de desplazamiento cultural en las ciudades latinomaericanas.

A esto, Hwang (2014) sugiere usar un enfoque colaborativo durante la planificación y ejecución del proyecto de regeneración urbana. Mientras que Rojas (2010b) indica que la herencia cultural y la identidad de un barrio requiere que los residentes conecten entre ellos identificando fechas, lugares, rituales, eventos e identificando lugares importantes para la comunidad.

La ciudad de Huancayo, especificamente, el espacio histórico denominado 15 de Junio, es un área central envejecida y que requiere medidas de intervención fundamentadas para el beneficio de la imagen urbana y de sus habitantes. Algunas de las causas del deterioro de las estructuras físicas y sociales de los barrios son la falta de mantenimiento de las viviendas, carencias estructurales, y la debilitación de las relaciones sociales entre los residentes (Rojas, 2010b). La situación negativa en las zonas urbanas históricas presenta problemas similares a los estudiados en otro tipo de barrios o secotres urbanos. Ademas, Suarez (2012) resalta que la renovación de áreas patrimoniales no debe ser excluyente ni obedecer solo a los intereses económicos de los inversionistas. Intervenciones basadas en intereses particulares terminan afectando las zonas históricas, alterando el paisaje o aprovechando las zonas concurridas para negocios no adecuados para las edificaciones.

La planificación de la ciudad debe enfocarse en proveer un seguro, organizado, un agradable hogar y vida laboral para los residentes de las áreas nuevas y consolidadas de la ciudad (Serag, Shalaby, Elsayed, \& Elariane, 2013). Antes que dominar el proceso de regeneración urbana, los planificadores deben alternar entre jugar un rol principal a uno suplementario en diferentes etapas del proceso. Rojas (2010a) indica que las municipalidades en latinoamérica juegan un rol prioritario pues estos gobiernos locales finanancian y diseñan los programas de mejora urbana. Tambien especifica que los programas de mejora de barrios son un camino directo para materializar el soporte del estado y necesitan metas claras y resultados medibles.

El objetivo de investigación es comprender la incidencia que han tenido las modificaciones en la infraestructura urbana sobre el estado de conservación de los inmuebles de Ambiente Urbano Monumental 15 de 
Junio de la ciudad de Huancayo durante el periodo de 1970 al 2019.

\section{La infraestructura urbana y la caminabilidad}

La infraestructura urbana con una orientación hacia el desarrollo de la caminabilidad conlleva multiples beneficios para la ciudad y el barrio. La mejora de la infraestructura peatonal y los equipamientos de servicios a peatones mejora significativamente la seguridad y la calidad del barrio (Yoshii, 2016). Además, Singh (2016) sostiene que en comunidades que son altamente caminables tienden a reducir el indice de criminalidad y a tener un incremento de las actividades económicas.

Esquivel-Cuevas, Hernández-Mercado y GarnicaMonroy (2013) señalan que es de gran importancia considerar la caminabilidad durante el diseño y gestión de proyectos urbanos. Además, autores como Raja y Zaharib (2013), Barros, Martinez, y Viegas (2017) o Singh (2016) afirman que la caminabilidad es la base de toda ciudad sostenible. Muchos otros investigadores coinciden y es posible asumir que el índice de caminailidad contribuye positivamente al desarrollo de una zona urbana.

La perceción del entorno caminable en la ciudad se ve alterada por los elementos construidos (Raja y Zaharib, 2013). Barros, Martinez, y Viegas (2017) sugieren que la forma urbana interfiere de forma significativa sobre el acto de caminar y que juega un rol mayor sobre otras variables como la conducta o los flujos peatonales. Singh (2016) apoya la idea de que la distribución de las edificaciones tienen un efecto de percecpción continua al caminar. Además, según Singh (2016), el uso de las edificaciones debe responder a la percepción del peatón y proporcionar un sentido de control sobre el espacio público. Barros, Martinez, y Viegas (2017) señalan que aparte de la forma urbana, otros factores relevantes son las escaleras y rampas.

A los efectos de la forma urbana, se suma los usos temporales del espacio. Guerín (2018) indica que la dinámica urbana nocturna y tienen un rol lúdico y en la búsqueda de estos espacios se suele caminar. Estas actividades implica una necesidad de un medio seguro para el peatón. Otro factor de gran importancia es el confort. A nivel individual, las personas necesitan estar cómodas en el espacio por el cual caminan, esto las motiva a ocupar los espacios públicos durante el día y la noche (Roussel, 2018).

El caso de estudio se sitúa en un área central y primigenia de la ciudad y una de las zonas altamente densificadas. Hwang (2014) señala que la gestión del crecimiento urbano puede darse en los centros urbanos envejecidos. Mertins (2018) indica que en renovaciones urbanas las medidas puede ser directas, de mejoramiento de la infraestructura, o indicrectas como la puesta en valor de las edificaiones de valor monumental. La revitalización de espacios patrimoniales urbanos es la aproximación mas resiliente para este espacios urbanos degradados (Samadi y Mohd, 2012). La morfología urbana, es un elemento predominante en el entendimiento de la ciudades latinoamericanas afectadas por una visión formalista modernista (Almandoz, 2006).

Especialmente en zonas urbanas antiguas, podemos encontrar calles estrechas junto a edificaciones de valor patrimonial, y estos lugares requieren especial atención para no ser descartados. Yoshii (2016) señala que corredores estrechos que cuentan con edificaciones de alto contenido cultural mercen ser separadas del tránsito vehicular y que se debe priorizar la interconexión de la red peatonal.

\section{La planificación urbana de la Zona Urbano Monumental de la ciudad de Huancayo}

Según Almandoz (2006), los altos niveles de urbanización en latinoamérica desde alrededor de 1980 a 2000 no estuvo acompañada por procesos de desarrollo. En este contexto en la ciudad de Huancayo se dieron cambios demográficos acelerados durante este periodo.

Como muestra la Tabla 1, durante el periodo de 1981 a 1993 la población huancaina creción con una tasa de 2.6\%, incrementando su población en 115842 habitantes en poco mas de una década. Ya en la última década, entre el periodo de 2007 al 2017 se registra una tasa de creciemiento de $1.6 \%$ al año. 


\section{Tabla 1}

Población censada en la Provincia de Huancayo 1981-2017

\begin{tabular}{|c|c|c|c|c|c|c|}
\hline \multicolumn{4}{|c|}{ Población censada } & \multicolumn{3}{|c|}{ Tasa de crecimiento anual (\%) } \\
\hline 1981 & 1993 & 2007 & 2017 & 1981-1993 & 1993-2007 & 2007-2017 \\
\hline 321549 & 437391 & 466346 & 545615 & 2.6 & 0.4 & 1.6 \\
\hline
\end{tabular}

Fuente: Elaboración propia en base a INEI (2018).

La ciudad de Huancayo cuenta con pocas plazas, las cuales están en el centro de la ciudad pero se conectan a través de una calle principal. Otros espacios cuentan con solo pequeñas plazas y las vías son los escenarios donde el comercio ambulatorio y los encuentros suelen suceder. Yoshii (2016) afirma que en lugares donde no se cuenta con un red estructurada de plazas, lo más apropiado es mejorar de las calles.

La disposición urbana de la ciudad de Huancayo concentra el tráfico vehicular en la parte central de la ciudad esta zona se superpone con la delimitación de la Zona Urbano Monumental (en adelante, ZUM) que según el Ministerio de Cultura (2016) constituye un área de valor patrimonial arquiectónico y urbano cuyo valor debe preservarse. La ZUM de Huancayo es suceptible a cambios en su infraestructura bajo intereses diversos debido a su conveniente ubicación.

El Ministerio de Cultura (2016) señala que el patrimonio inmueble son edificaciones o ambientes urbanos, entre ellos los centros históricos, que muestren evidencias resaltantes de la vida y actividad humana urbanos o rural. El área de estudio esta en el corazón del centro urbano presentandose como un espacio distinto con contenido histórico. Sánchez, Teutli y Maximiliano (2016) explican que el valor urbano, funcional y simbólico de los centros históricos tienen una relación dinámca interrelacionada. Asimismo, Mària y Salvadó (2017, p.30) señalan que conservar el patrimonio construido evita el uso de recursos y energía que generan las tareas de demolición y reconstrucción.

Para el Ministerio de Cultura (2016) un monumento arquitectónico tiene un valor cultural, artístico, histórico y social; por ello está protegido por la legislación nacional, evitando su destrucción. Sin embargo, esta posición está acompañada de escazas soluciones para la puesta en valor del monumento y el entorno de este en la ZUM de la ciudad de Huancayo.

La Figura 1 muestra la delimitación de la ZUM de Huancayo y la ubicación de los monumentos declarados por el Ministerio de Cultura. Los monumentos históricos que se encuentran dentro de la zona monumental se encuentran agrupados en tres ambientes urbanos con potencial de convertirse en ambientes urbanas monumentales. 
(1) AU Constitución

(2) AU 15 de Junio

(3) AU Arequipa

(2) Centro Cívico

(-) Mercado de Abastos

- Catedral y Plaza

Espacio urbano que agrupa inmuebles de valor patrimonial

Monumentos patrimonial

Inmuebles con valor

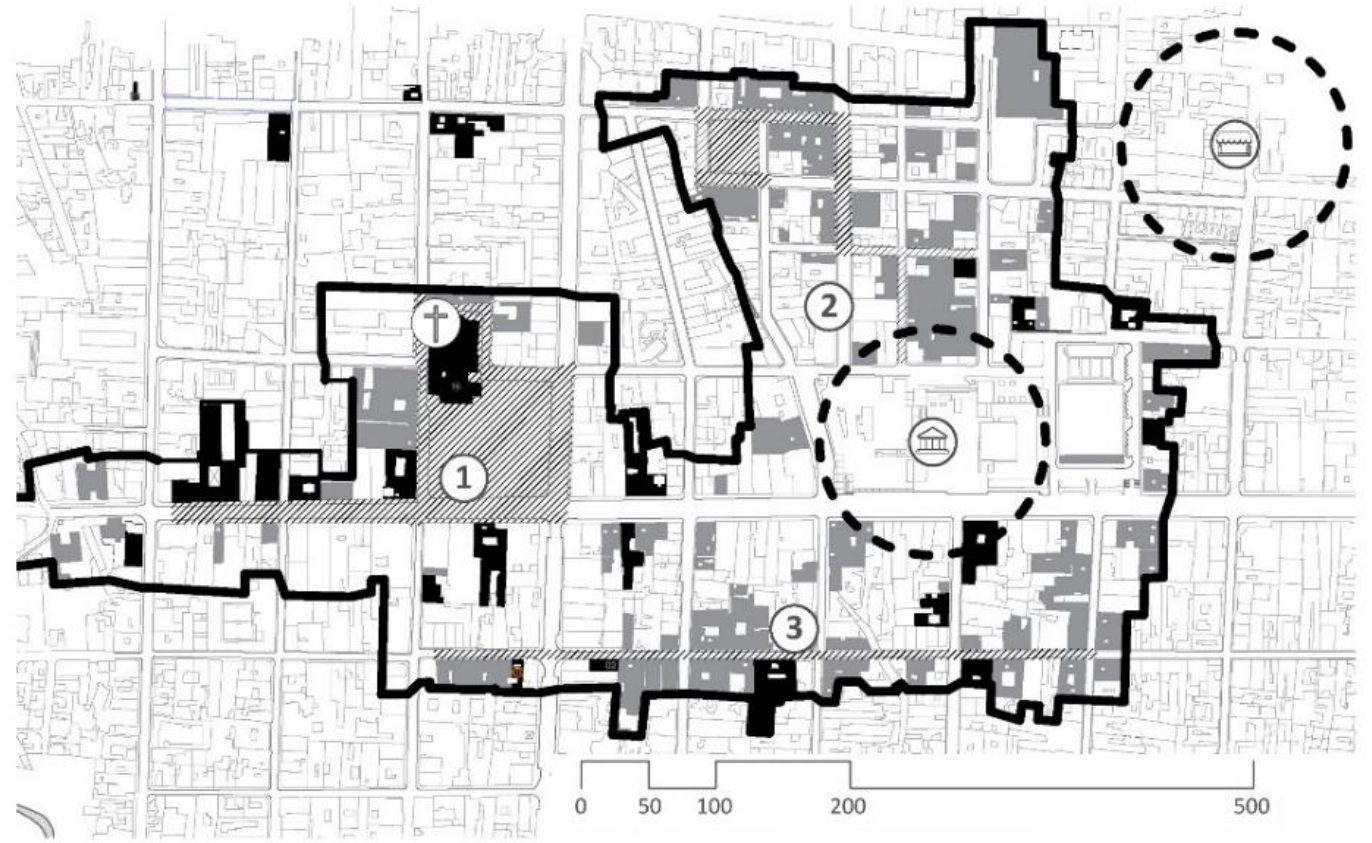

Figura 1. Zona Urbano Monumental de la ciudad de Huancayo. Fuente: Elaboración propia.

Existe un bajo compromiso de la inclusión del entorno inmediato a los inmuebles con valor patrimonial en la ciudad de Huancayo. Concha y Concha (2014) señalan que la industria inmobiliaria y la falta de conocimiento del patrimonio cultural ha causado el deterioro de muchos inmuebles y su demolición. La Figura 2 muestra un ejemplo de monumento en el área de estudio, se puede distinguir el estado de fachada y los usos inadecuados.

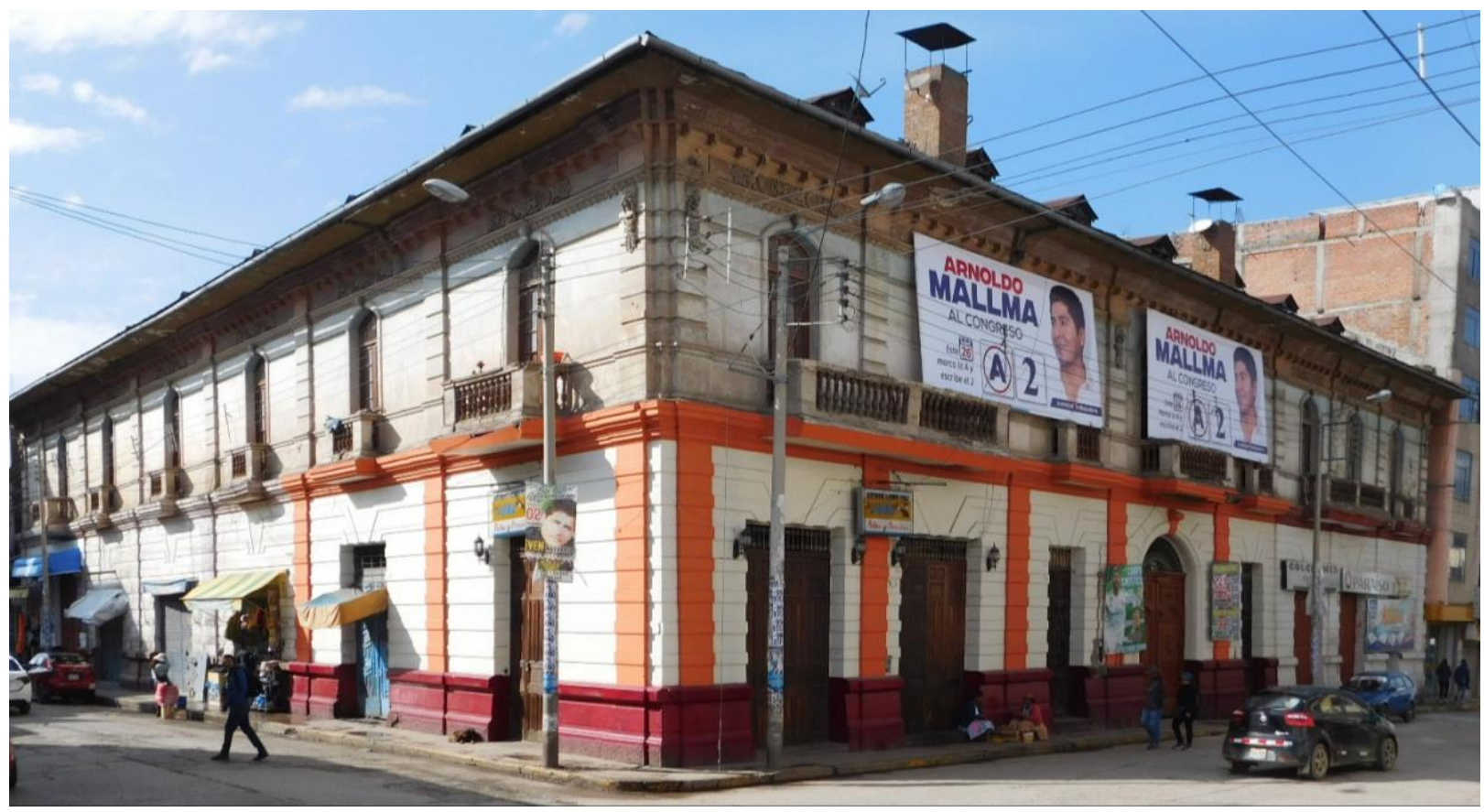

Figura 2. Edificación patrimonial representativa en el área de estudio. Fuente: Fotografía tomada en noviembre del 2019. 
Por otro lado, se distingue que en el centro de la ciudad existe una estructura de movilidad heterogenea en la que existe una competencia entre el peatón, el comercio ambulatorio y los automóviles. Existe una irregularidad deficiente entre tramos de vía en los que por instantes se distingue la ausencia de aceras. Gallego (2016) señala que la falta de espacios públicos conectados dentro de un área y la red de espacios públicos en la ciudad limitan las interrelaciones con áreas cercanas.

Tanto Lavrov, Perov, y Eremeeva (2018) como Sánchez, Teutli y Maximiliano (2016) afirman que las zonas con valor histórico deben integrarse a la ciudad a través de sus espacios públicos y que se debe actuar con un enfoque sostenible. Las intervenciones de mejora municipal del AUM 15 de Junio priorizaron el ensanche de vías como solución de integración.

Para Dinardi (2015), durante las intervenciones urbanas que involucran patrimonios inmuebles existe una competencia de intereses que debe ser resuelta. Versaci (2016) alienta las iniciativas de apoyo a la conservación del patrimonio cultural debido a este requiere mejoras $y$ desarrollo del entorno en el que se encuetra. Cheng, Dang y Peng (2014) consideran el rol de las zonas con valor patrimonial como espacios de conservación y recreación que en grandes corredores pueden tener un valor turístico.

Zhang, Lu y Song (2012) enlistan responsabilidades de los actores princiales como: el gobierno debe comprender las politicas favorables y el soporte financiero; los grupos culturales soportan la red de comunicación cultural; los organismos culturales proveen financiamiento y servicios internos; y los residentes estarían involucrados con actividades voluntarias y de monitoreo.

\section{El Ambiente Urbano Monumental 15 de Junio}

Según Ministerio de Cultura (2016), un Ambiente Urbano Monumental (en adelante, AUM) es un espacio urbano compuesto por vias, plazas u otros espacios públicos que relacionan inmuebles de valor patrimonial. Asi que es posible definir o proponer un AUM en base a las características de sus espacios públicos y edificiaciones.

El AUM 15 de Junio es parte central de la AUM de Huancayo a unos 300 metros de la plaza principal de Huancayo, limita con la plaza Huamanmarca a cuyos lados se ubican la Municipalidad provincial de Huancayo y el palacio de Gobierno Regional de Junín; además ofrece un acceso directo hacia la zona comercial del mercado central de la ciudad. Con respecto de la tipología del patrimonio, Concha y Concha (2014) identifican que la interpretación arquitectónica y tipologías de patrimonio monumental se encuentran estrechamente relacionadas y esto se debe en parte al momento de construcción de los inmuebles los cuales son de origen republicano.

La Figura 3 muestra de forma general la condición de algunas vías del espacio urbano del AUM 15 de Junio. En la actualidad, es un espacio urbano degradado, con actividad comercial durante el día acondicionada de forma precaria y que durante la noche en sus calles se pueden ver grupos de prostitutas y residuos sólidos esparcidos por la vía. Esta primera impresión del sitio de estudio se muestra como la imagen del lugar para los residentes de la ciudad. Sin embargo, estos espacios contienen una cantidad importante de inmuebles con características arquitectónicas representativas de la historia de la ciudad y que guardan gran similitud con los examinados por Concha y Concha (2014). 


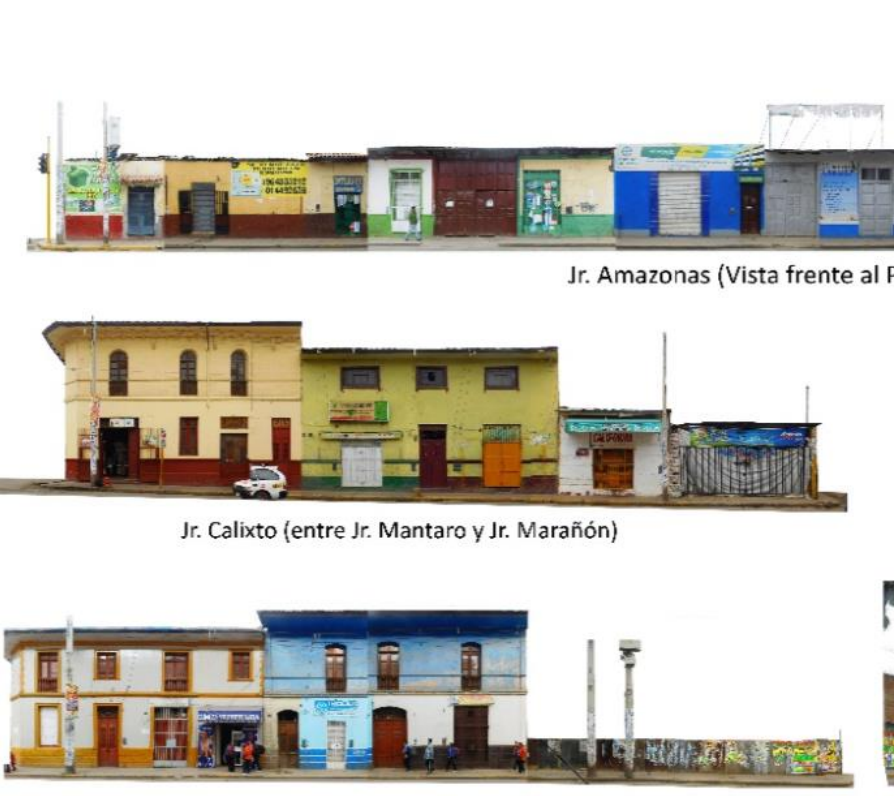

Jr. Amazonas (Esquina Jr. Calixto)

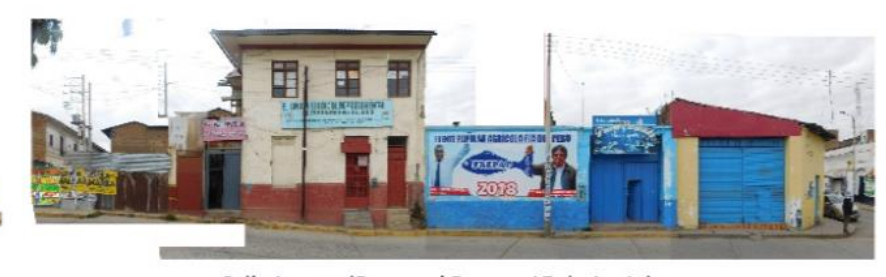

Calle Loreto (Frente al Parque 15 de Junio)

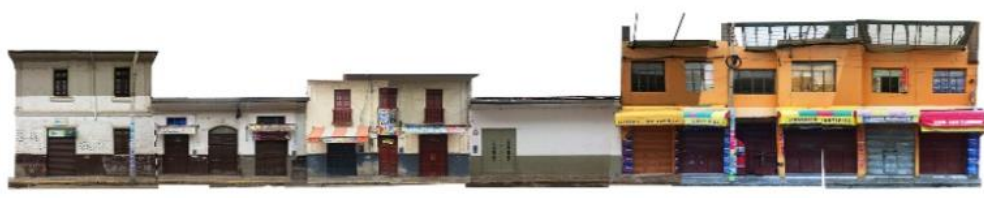

Jr. Marañón (entre Jr. Ica y Jr. Huamanmarca)

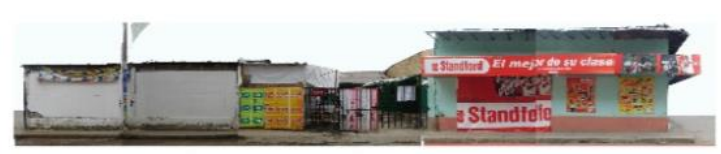

Jr. Marañón (entre Jr. Calixto y Jr. Huamanmarca)

Figura 3. Vistas de edificaciones en las vías Calixto y Amazonas del AUM 15 de Junio. Fuente: Composición elaborada con fotografías capturadas en noviembre del 2018.

\section{Metodología}

La investigación atiende al problema ¿De qué manera las modificaciones en la infraestructura urbana inciden sobre el estado de conservación de los inmuebles del ambiente urbano monumental 15 de Junio de la ciudad de Huancayo durante el periodo de 1970 al 2019.

Para Cheng, Dang y Peng (2014) las zonas de intervención con valor patrimonial deben limitarse adecuadamente tomando en cuenta la autenticidad e integridad, consideraciones técnicas, y la estimación en términos económicos y administrativos. Por ello, el primer paso fue la propuesta de delimitación del AUM 15 de Junio. Según Ministerio de Cultura (2016), la delimitación de los Ambientes Urbano Monumentales (AUM) es aprobada por el Ministerio de Cultura. En este caso el AUM 15 de Junio no cuenta con una definición oficial; sin embargo, esta debe estar contemplada dentro de la limitación de la actual Zona Monumental de la ciudad de Huancayo. La Figura 4 muestra la delimitación propuesta del ambiente urbano monumental que es resultado de un exhaustivo estudio de la zona, proceso que contó con el apoyo de la dirección desconcentrada de cultura Junín y las consultas técnicas correspondientes. 


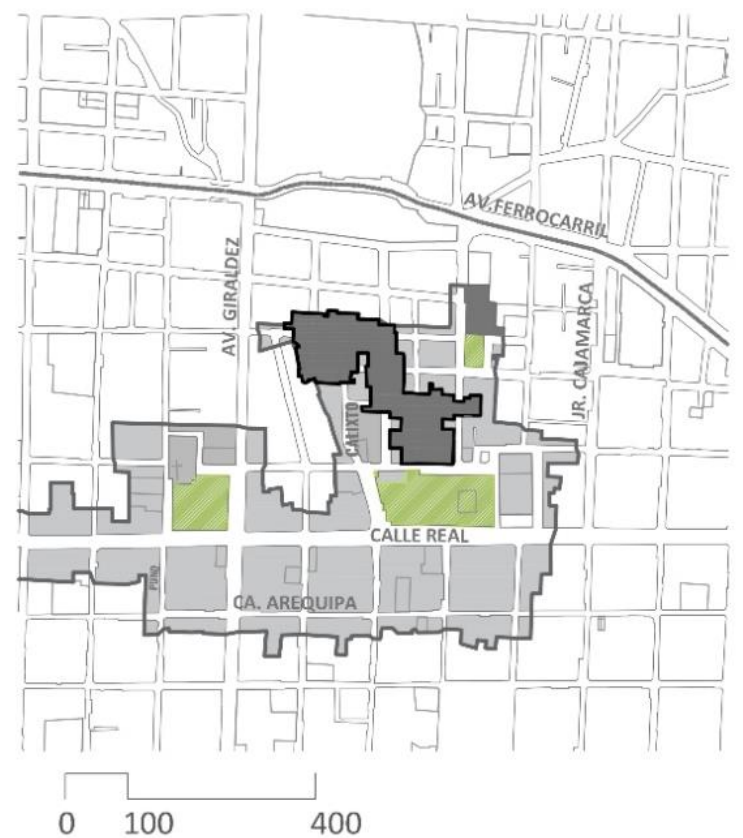

Espacios públicos de estancia (plazas y parques)

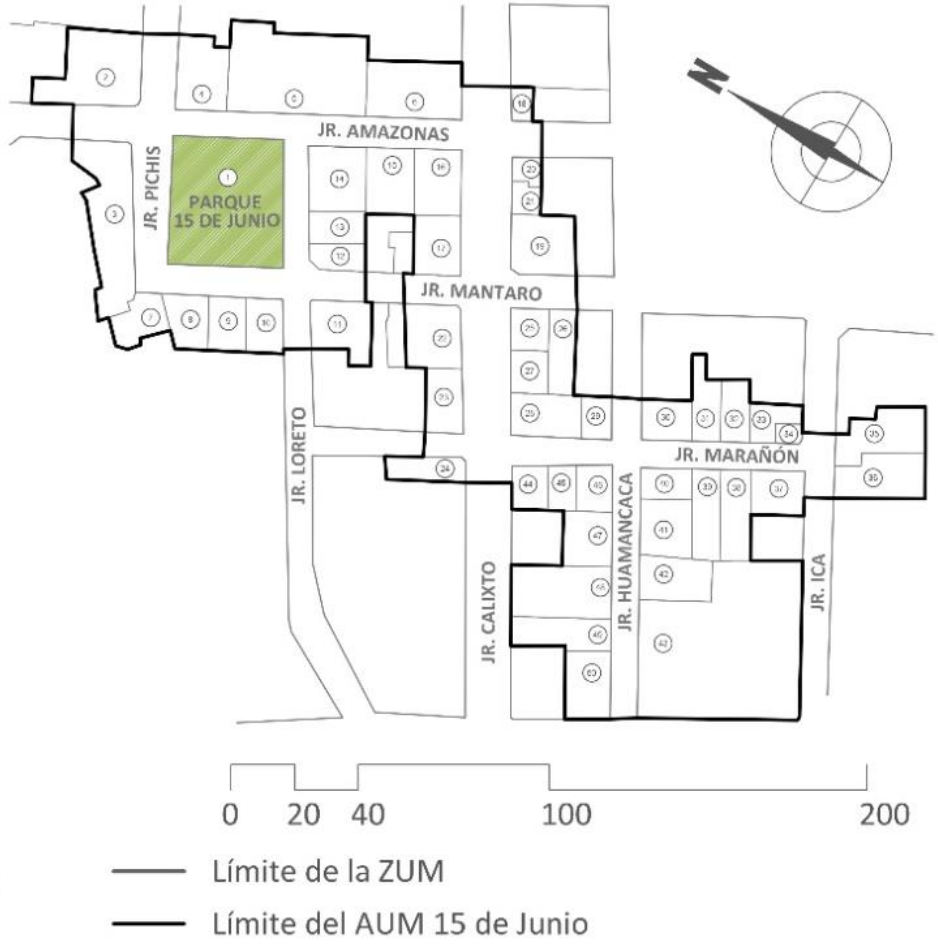

Figura 4. Limite propuesto del Ambiente Urbano Monumental 15 de Junio. Fuente: Elaboración propia

La Figura 4 muestra la ubicación y delimitación del sector de estudio. El AUM 15 de Junio está compuesto de 50 elementos de estudio entre inmuebles y parques o plazas. Es necesario aclarar que algunas unidades arquitectónicas están en posesión de varias personas y que existen divisiones internas. Algunas veces, estas divisiones pueden ser informales, por lo que se ha considerado la unidad arquitectónica como criterio para la medición de las variables.

El estudio considera el análisis de una diversidad de variables independientes agrupadas en categorías cuya medición se genera de la reconstrucción del estado de la infraestrucura urbana del sitio en estudio con el objetivo de medir su incidencia en el estado de conservación patrimonial de los inmuebles de la AUM 15 de Junio.

Se utilizaron diversos medios para la recolección de datos, pero principalmente, se condujo 12 entrevistas semiestructuradas a ciudadanos que residen en el área por más de 50 años y que están estrechamente vinculados al desarrollo urbano del lugar, estas fueron conducidas entre octubre del 2018 a mayo del 2019. La entrevista se dividió en dos etapas: la primera sirvió para identificar la evolución general del entorno urbano y la segunda para indagar en los detalles de cada una de las 50 edificaciónes. Se reforzaron los hallazgos a través de opiniones técnicas del personal de la Dirección Descentralizada de Cultura de la Región Junín. Para poder establecer una relación fundamentada, los datos del estado actual de cada inmueble se contrastan con los recuperados de las entrevistas y documentación disponible. Este registro se reconstruyó en periodos de cinco años.

Las variables independientes. Se agrupan siete vaiables en las dimensiones: forma urbana, espacio público, uso de edificación. Las variables y los valores de su medición se detallan en la Tabla 2.

La forma urbana urbana agrupa la medición de criterios físicos identificables y cuya reconstrucción es posible a través de entrevistas, mapas o imágenes. Basados en criterios de promoción de la caminabilidad y cuya medición es atendida en los estudios de EsquivelCuevas Hernández-Mercado y Garnica-Monroy (2013), y Rafiemanzelata \& Emadib (2017). Los criterios de valoración se darán en una escala del 1 al 5, en promoción de la caminabilidad asumiendo su importancia dentro de un saludable y sostenible desarrollo urbano. Dado que la 
forma urbana es una composición geométrica de elementos como calles, edificicaciones, fachadas, mobiliario urbano, vegetación entre otros (Barros, Martinez, y Viegas, 2017). El estudio del estado de la forma urbana en el área de estudio tomó en consideración estos elementos.

Aunque, Dinardi (2015) sostiene que el valor de un inueble conlleva un factor de carácter subjetivo importante. Un sondeo del lugar resalto un valor de suelo con poca variación, por lo que, en este caso, no fue considerado.

El espacio público y su uso agrupa la característica de uso de las vías y espacios de estancia como parques y plazas distinguiendo su uso durante el día y la noche. Esto scriterios tambien son considerados por Esquivel-Cuevas, Hernández-Mercado y Garnica-Monroy (2013), y Rafiemanzelata \& Emadib (2017). La presente investigación sugiere la medición de sus variables bajo un enfoque explicativo e histórico que resalta la forma en que el espacio fue utilizado en el pasado en las áreas correspondientes a las edificaciones del AUM 15 de Junio.

El uso de edificación enfatiza la categorización bajo la perspectiva de promover la caminabilidad a través de la aproximación de usos mixtos y en el que se prioriza la presencia de viviendas y desarrollo económico con servicios con un enfoque de atención a los transeuntes, promoviendo la caminabilidad del lugar.

Las dimensiones consideradas para la evaluación del índice de caminabilidad para el área en estudio se se presenta en la Tabla 2.

La medición de los indicadores enlistados en la Tabla $\underline{2}$, se realizaron mediante un sistema de escala de calificación del 1 al 5 para cada variable, siendo el valor de 1 el de mayor efecto negativo y 5 el de mayor efecto positivo.

La variable dependiente. Es el estado de conservación de los inmuebles con valor patrimonial. Esta variable, se cree, es influenciada por la infraestructura urbana en la zona. Su medición ayudará a identificar el nivel de deterioro que los inmuebles con valor patrimonial y de entorno han sufrido a causa de las modificaciones en la infraestructura urbana.
Acierno, Cursi, Simeone \& Fiorani (2017) proponen un marco de estudio para la representación de patrimonios arquitectónicos que permite la estandarización del estudio de este tipo de inmuebles bajo la agrupación de sus características en dominios. Dentro del modelo el estudio se enfoca en la identificación de dos de los dominios; el primero es el dominio del ciclo de vida del artefacto que involucra las acciones de modificación física del inmueble a través del tiempo; y el dominio del diseño del artefacto, identificando solo las características básicas de su composición como unidad arquitectónica, sus componentes arquitectónicos y material de construcción. Esta perspectiva se ha considerado arcialmente para la evaluación de las características arquitectónicas, materiales, el uso de la edificación entre otros indicados en la Tabla 3.

La medición de los indicadores enlistados en la Tabla $\underline{3}$, se realizaron mediante un sistema de escala de calificación del 1 al 5 para cada indicador, siendo el valor de 1 para el estado de menor conservación y 5 el de mayor estado de conservación. De la calificación obtenida, se realizará la multiplicación por el factor asignado a cada indicador de la siguiente forma:

$$
\begin{aligned}
& a=\sum_{j=1}^{n} I_{e j} F I_{j} \\
& N C_{e}=\left\{\begin{array}{l}
1 \mid 1.0 \leq a<1.8 \\
2 \mid 1.8 \leq a<2.6 \\
3 \mid 2.6 \leq a<3.4 \\
4 \mid 3.4 \leq a<4.2 \\
5 \mid 4.2 \leq a \leq 5.0
\end{array}\right.
\end{aligned}
$$

Donde:

$\mathrm{NC}_{\mathrm{e}}$ : Nivel de conservación de la edificación e.

$\mathrm{I}_{\mathrm{ej}}$ : Valoración de estado del indicador j del lote $\mathrm{E}$

$F_{\mathrm{ej}}$ : Factor del indicador $\mathrm{j}$.

Se utilizó un modelo de regresión linear jerárquica para evaluar si las dimensiones de interés de la variable independiente tienen una incidencia estadísticamente significativa sobre la predictibilidad de la variable dependiente. De esta forma, se puede comparar modelos simples e identificar las dimensiones de los cambios en la infraestructura urbana que influyen más sobre el estado de conservación de los inmuebles con valor patrimonial en el AUM 15 de Junio. 


\section{Tabla 2}

Dimensiones de la infraestructura urbana, variables independientes y sus valores de medición

\begin{tabular}{|c|c|c|}
\hline Dimensión & Variable & Valores \\
\hline \multirow{20}{*}{ Forma urbana } & \multirow{5}{*}{ Tamaño de la acera. } & 1: Menos de $1 \mathrm{~m}$ de ancho. \\
\hline & & 2: Entre 1 a $2 \mathrm{~m}$. de ancho. \\
\hline & & 3: Entre 2 a $3 \mathrm{~m}$ de ancho. \\
\hline & & 4: Entre 4 a $5 m$ de ancho. \\
\hline & & 5: Mayor a $5 \mathrm{~m}$ de ancho. \\
\hline & \multirow{5}{*}{ Facilidad de cruce } & 1: Alta prescencia vehicular y sin control por semáforos u otros. \\
\hline & & 2: Baja prescencia vehicular sin control de semáforos u otros. \\
\hline & & 3: Alta prescencia vehicular con control de semáforos u otros. \\
\hline & & 4: Baja prescencia vehicular con control de semáforos u otros. \\
\hline & & 5: Muy baja o ningún tipo de presencencia vehicular. No requiere semaforización \\
\hline & \multirow{5}{*}{$\begin{array}{l}\text { Obstáculos verticales u } \\
\text { horizontales en aceras }\end{array}$} & 1: Presencia de elementos obstructivos que invaden la via y no permiten caminar en ella. \\
\hline & & $\begin{array}{l}\text { 2: Presencia de elementos en la acera que deben ser evadidos saliendo de la acera o a través de alguna } \\
\text { maniobra para poder continuar caminando. }\end{array}$ \\
\hline & & $\begin{array}{l}\text { 3: Presencia de algunos elementos en la vía que pueden ser evadidos con facilidad sin bajarse de la } \\
\text { acera. }\end{array}$ \\
\hline & & 4: Presencia de pocos elementos en la via que reducen el espacio de forma poco significativa. \\
\hline & & 5: Veredas libres de obstáculos. \\
\hline & \multirow{5}{*}{$\begin{array}{l}\text { Presencia de arbolado y } \\
\text { áreas verdes }\end{array}$} & 1: Ningun área verde a la vista. \\
\hline & & 2: Áreas verdes de menores como grass u otros similares visibles. \\
\hline & & 3: Presencia de arbustos pequeños, flores y elementos verdes similares. \\
\hline & & 4: Prescencia de árboles y áreas verdes como elementos solo ornamentales. \\
\hline & & 5: Presencia de árboles y áreas verdes que ofrecen puntos de protección solar o recreación. \\
\hline \multirow{10}{*}{$\begin{array}{l}\text { Espacio } \\
\text { público }\end{array}$} & \multirow{5}{*}{$\begin{array}{l}\text { Uso diurno del espacio } \\
\text { público. }\end{array}$} & 1: Invasión del espacio con materiales de descarga o de comercio que impide sus uso con normalidad. \\
\hline & & 2: Uso del espacio público para el comercio ambulatorio no planificado. \\
\hline & & 3: Espacio libre para usos regulares. \\
\hline & & 4: Promoción del comercio organizado o amenidades públicas. \\
\hline & & 5: Promoción de actividades culturales en harmonía con el uso del espacio público. \\
\hline & \multirow{5}{*}{$\begin{array}{l}\text { Uso nocturno del espacio } \\
\text { público }\end{array}$} & $\begin{array}{l}\text { 1: Encuentros nocturnos que involucran la presencia de grupos delincuenciales, prostitución, entre } \\
\text { otros. }\end{array}$ \\
\hline & & 2: Enceuntros nocturnos entre grupos aislados que promueven actividades ilegales . \\
\hline & & $\begin{array}{l}\text { 3: Poco o ningún estimulo para encuentros sociales entre los residentes de la zona, pero con auscencia } \\
\text { de actividades ilícitas }\end{array}$ \\
\hline & & 4: Generación de encuentros sociales medianamente frecuentes. \\
\hline & & 5: Generación de encuentros sociales y eventos en harmonía con la vida residencial \\
\hline \multirow{5}{*}{$\begin{array}{l}\text { Uso de la } \\
\text { edificación }\end{array}$} & \multirow{5}{*}{$\begin{array}{l}\text { Uso de edificación (en } \\
\text { función de la promoción de } \\
\text { usos beneficos para la } \\
\text { caminabilidad y promoción } \\
\text { social) }\end{array}$} & 1: Actividad informal. \\
\hline & & 2: Industrial (mecánica, ferretería, molienda, comercio con alta carga descarga). \\
\hline & & 3: Comercios especializado (librería, tarjetas, entre otros). \\
\hline & & 4: Servicio especializado (restaurante, café, bar, salon de belleza, librería, oficinas entre otros). \\
\hline & & 5: Vivenda solamente o con actividad económica. \\
\hline
\end{tabular}

Fuente: Elaboración propia 


\section{Tabla 3}

Indicadores utilizados y peso relativo para el cálculo de estado de conservación patrimonial

\begin{tabular}{|c|c|c|}
\hline Dimensión & Indicador & Factor \\
\hline \multirow[t]{2}{*}{ Atractivo arquitectónico } & $\mathrm{I}_{1}:$ Integridad espacial & 0.30 \\
\hline & $\mathrm{I}_{2}$ : Fachada, puertas y ventanas & 0.20 \\
\hline \multicolumn{3}{|c|}{ Estado de elementos construidos } \\
\hline & $\mathrm{I}_{3}:$ Estructura & 0.20 \\
\hline & $\mathrm{I}_{4}$ : Compatibilidad de uso actual & 0.15 \\
\hline \multicolumn{3}{|c|}{ Uso y tenencia de la edificación } \\
\hline & $\mathrm{I}_{5}$ : Capacidad de gestión con porpietario & 0.15 \\
\hline
\end{tabular}

Fuente: Elaboración propia.

\section{Resultados: Dinámica en el AUM 15 de Junio}

El desarrollo del AUM 15 de Junio en las últimas cinco décadas puede dividirse en cuatro etapas diferenciadas. La Figura 5 muestra una aproximación a la evolución del
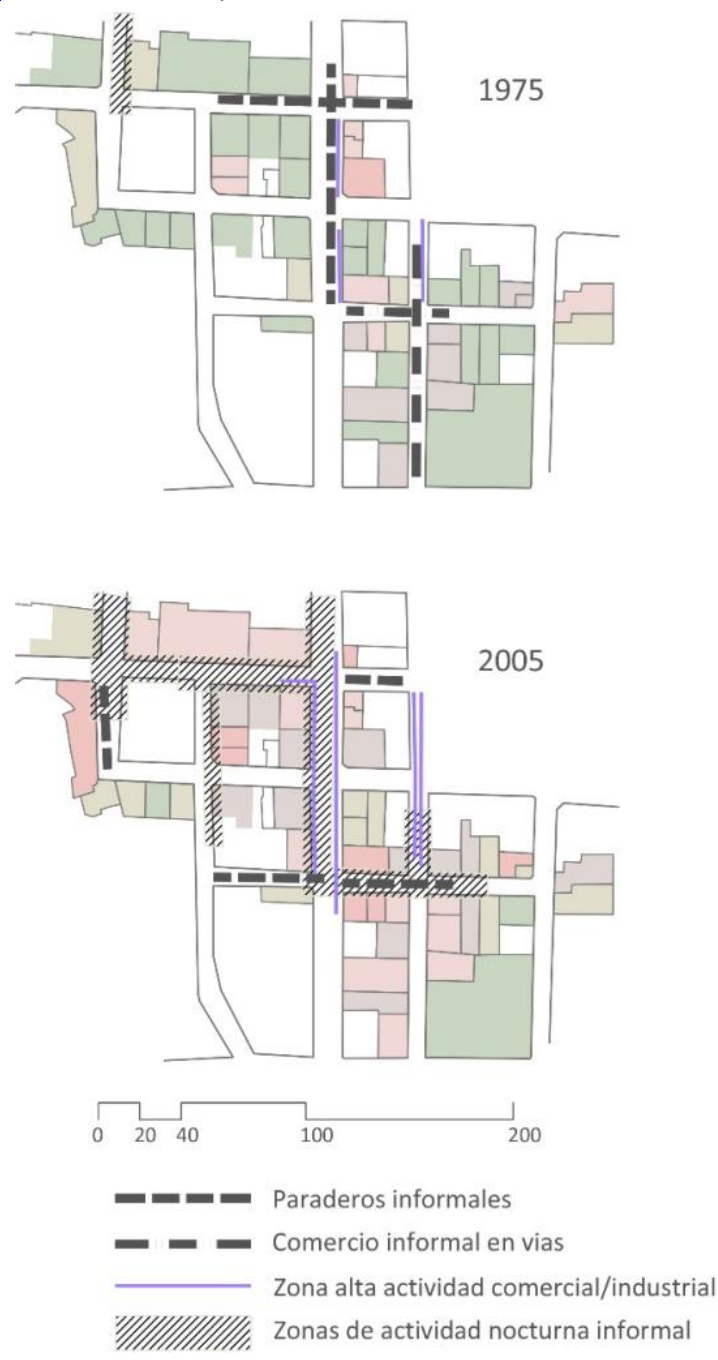

estado de conservación y los cambios en la concentración de zonas comerciales y con actividad nocturna descritos en las etapas de evolución del AUM 15 de Junio.
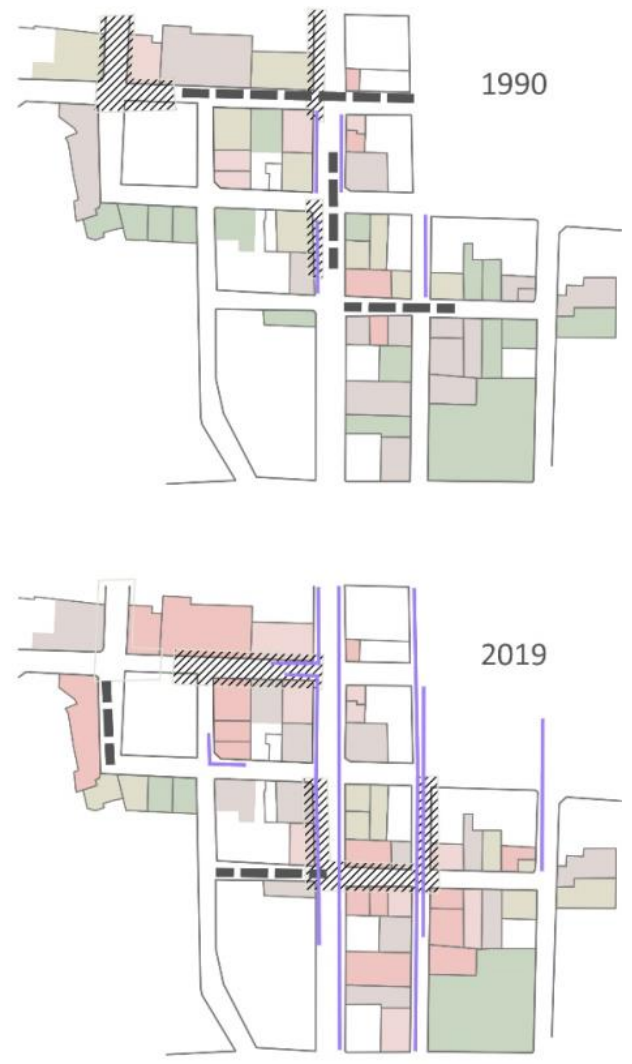

N. conservación (1 - muy malo)

N. conservación (2 - malo)

N. conservación (3 - regular)

N. conservación (4 - bueno)

N. conservación (5 - muy bueno)

Figura 5. Años representativos de la dinámica espacial del AUM 15 de Junio. Fuente: Elaboración propia 
Primera etapa (1970-1980). Durante los inicios de la década de los setentas, los acontecimientos serían locales y la integración con otras partes de la ciudad ocurriría de forma lenta y se introducirían usos industriales como la aparición de un aserradero en la avenida Calixto, la instalación de terminales informales hacia Jauja, La Oroya y Lima en las calles Amazonas y Calixto. El principal aporte de la autoridad local, señalan numerosos residentes se centró en el asfaltado de las vías alrededor de 1972 y 1975. Caminos antes transitables a pie comenzarían a integrarse a una red vehicular.

Segunda etapa (1980-1990). Es en esta época donde pequeños establecimientos aparecerían y se reforzaría la aparición de ferreterías, comercialización de productos agrícolas y el uso de la vía Huamanmarca para la comercialización de productos como el maíz y granos alrededor de 1985 a 1990. El espacio público enfrentaría una especie de invasión por personas ajenas a la zona y cierta molestia y oportunidades para negocios que los residentes locales avistarían y que se traducen en la aparición de aperturas para nuevos locales. Ningún esfuerzo por la regulación del uso de las edificaciones fue comentado durante las entrevistas, pero si un fuerte rechazo por la comercialización de granos y otros productos en la vía

Tercera etapa (1990-2010). En esta etapa existe una migración y traspaso de los inmuebles a herederos familiares o a sus servidores domésticos. En busca de un beneficio económico, los propietarios de la zona, incentivados por una floreciente economía local y negocios relacionados a la venta de productos agrícolas y la venta de útiles de escritorio, buscan la apertura de una diversidad de pequeños establecimientos. Algunos otros alquilan los espacios disponibles de las casas que ya no habitaban.

Durante el proceso evolutivo del lugar, las autoridades locales centran su atención en la regulación del tráfico y el asfaltado de vías. Por otro lado, se da inicio a la apertura de establecimientos de hospedaje informales para actividades relacionadas a la prostitución que se daban en zonas cercanas como las calles Yali o Loreto. Los altos ingresos económicos y la carencia de regulación urbana alentaron a nuevos propietarios en el desarrollo de este negocio el cual floreció rápidamente. La zona sería conocida ampliamente por los servicios nocturnos en toda la ciudad. Algunas intervenciones policiales logran reducir el creciente mercado informal de prostitución, pero la imagen urbana quedaría presente al final de esta etapa.

Cuarta etapa (2010-2019). En esta etapa se afecta permanentemente algunas de las edificaciones y se inicia un proceso de demolición y consolidación de las divisiones de los inmuebles alterándolos dramáticamente. Las políticas urbanas locales se centraron en la reorganización del tráfico y limpieza de vías.

\section{El nivel de conservación}

Los indicadores descriptivos de la revisión de la variable nivel de conservación, se presentan en la Tabla 4 , agrupados por año. 
Tabla 4:

Indicadores utilizados y peso relativo para el cálculo de estado de conservación

\begin{tabular}{|c|c|c|c|c|c|c|c|}
\hline Año & Indicador & $\begin{array}{c}\mathrm{I}_{1} \text { : Integridad } \\
\text { espacial }\end{array}$ & $\begin{array}{l}\mathrm{I}_{2}: \text { Fachada, } \\
\text { puertas y } \\
\text { ventanas }\end{array}$ & $\mathrm{I}_{3}:$ Estructura & $\begin{array}{l}\mathrm{I}_{4} \text { : Compatibilidad } \\
\text { de uso actual }\end{array}$ & $\begin{array}{l}\text { I }_{5} \text { : Capacidad de } \\
\text { gestión con } \\
\text { porpietario }\end{array}$ & $\begin{array}{l}\text { NC: Nivel de } \\
\text { conservación }\end{array}$ \\
\hline \multirow[t]{3}{*}{1970} & Media & 3.98 & 3.76 & 3.84 & 3.94 & 4.46 & 4 \\
\hline & Mediana & 4.5 & 4.5 & 4.5 & 5 & 5 & 5 \\
\hline & Moda & 5 & 5 & 5 & 5 & 5 & 5 \\
\hline \multirow[t]{3}{*}{1975} & Media & 3.88 & 3.7 & 3.76 & 3.94 & 4.5 & 4 \\
\hline & Mediana & 4 & 4 & 4 & 4.5 & 5 & 5 \\
\hline & Moda & 5 & 5 & 5 & 5 & 5 & 5 \\
\hline \multirow[t]{3}{*}{1980} & Media & 3.84 & 3.7 & 3.78 & 3.9 & 4.36 & 3.98 \\
\hline & Mediana & 4 & 4 & 4 & 4 & 5 & 5 \\
\hline & Moda & 5 & 5 & 5 & 5 & 5 & 5 \\
\hline \multirow[t]{3}{*}{1985} & Media & 3.6 & 3.54 & 3.64 & 3.64 & 4.02 & 3.84 \\
\hline & Mediana & 4 & 4 & 4 & 4 & 4 & 4 \\
\hline & Moda & 5 & 4 & 5 & 4 & 5 & 5 \\
\hline \multirow[t]{3}{*}{1990} & Media & 3.4 & 3.3 & 3.42 & 3.46 & 3.62 & 3.6 \\
\hline & Mediana & 3.5 & 3.5 & 4 & 4 & 4 & 4 \\
\hline & Moda & 4 & 4 & 4 & 3 & 4 & 5 \\
\hline \multirow[t]{3}{*}{1995} & Media & 3.22 & 3.22 & 3.12 & 3.22 & 3.04 & 3.3 \\
\hline & Mediana & 3 & 3 & 3 & 3 & 3 & 3 \\
\hline & Moda & 4 & 3 & 4 & 3 & 2 & 3 \\
\hline \multirow[t]{3}{*}{2000} & Media & 2.94 & 2.96 & 3 & 2.96 & 2.6 & 2.98 \\
\hline & Mediana & 3 & 3 & 3 & 3 & 2 & 3 \\
\hline & Moda & 2 & 4 & 4 & 3 & 2 & 4 \\
\hline \multirow[t]{3}{*}{2005} & Media & 2.86 & 2.74 & 2.86 & 2.62 & 2.42 & 2.8 \\
\hline & Mediana & 3 & 3 & 3 & 2 & 2 & 3 \\
\hline & Moda & 3 & 3 & 3 & 2 & 2 & 3 \\
\hline \multirow[t]{3}{*}{2010} & Media & 2.7 & 2.44 & 2.86 & 2.46 & 2.2 & 2.54 \\
\hline & Mediana & 3 & 3 & 3 & 2 & 2 & 3 \\
\hline & Moda & 1 & 3 & 3 & 2 & 1 & 1 \\
\hline \multirow[t]{3}{*}{2015} & Media & 2.64 & 2.38 & 2.8 & 2.46 & 2.2 & 2.52 \\
\hline & Mediana & 3 & 2.5 & 3 & 2 & 2 & 3 \\
\hline & Moda & 1 & 3 & 3 & 2 & 1 & 1 \\
\hline \multirow[t]{3}{*}{2019} & Media & 2.64 & 2.38 & 2.8 & 2.44 & 2.16 & 2.54 \\
\hline & Mediana & 3 & 2 & 3 & 2 & 2 & 3 \\
\hline & Moda & 1 & 3 & 3 & 2 & 1 & 1 \\
\hline
\end{tabular}

Fuente: Elaboración propia 


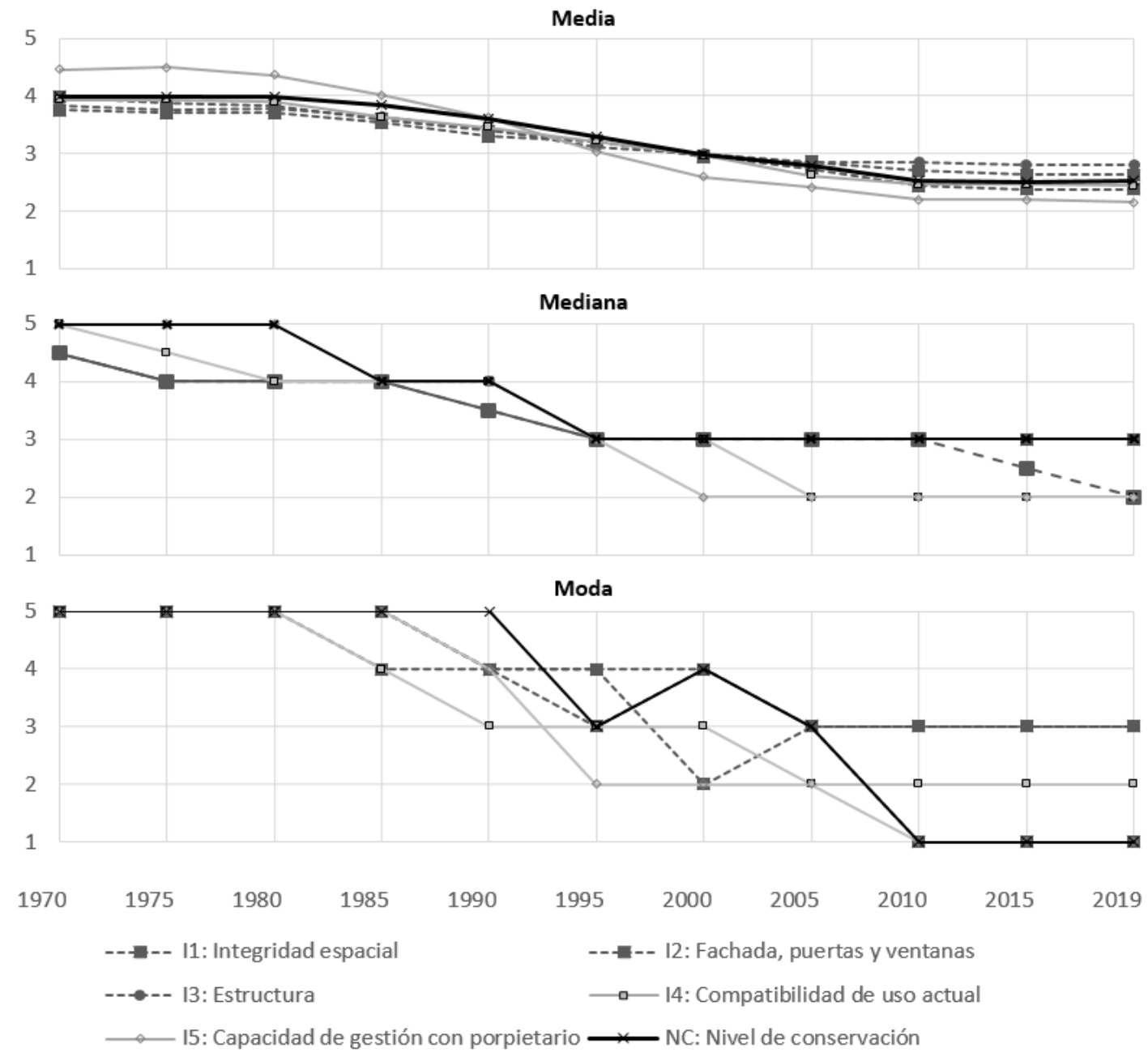

Figura 6. Evolución de los indicadores de la variable dependiente Nivel de conservación. Fuente: Elaboración propia

La evolución de los resultados de los indicadores de la variable nivel de conservación revelan una gradual disminución del estado de conservación desde la década de 1970 al periodo actual como se visualiza en la Figura 6. La media del indicador 15 presente una conducta particular en su media, con puntuación máxima de 4.46 en el año 1970, manteniéndose hasta el año 1985 con 4.02, se distingue una disminución importante hacia el año 2000 en el que llega al 2.6, disminuyendo lentamente hasta el año 2019 con una media de 2.16. La media del indicador I1 Integridad espacial obtiene un máximo de 9.98 en el año 1970, llegando a un valor de 3.22 en el año 1995 y disminuyendo gradualmente hasta 2.64 en el 2015.
Por otro lado, la mediana y la moda de los indicadores muestran una conducta significativamente diferente a partir del año 1990, en el que se muestra una caída importante del indicador 15 de una moda de 4 en 1990 a una moda de 2 hacia el año 1995. El indicador I1 también muestra una marcada disminución posterior al año 1995, con una moda de 4 en el año 1995 y una moda de 2 hacia el año 2000.

Con respecto al análisis individual de las edificaciones, la variable nivel de conservación presenta una tendencia de degradación. La Figura 7 muestra el mayor nivel alcanzado, el menor nivel alcanzado y el nivel de conservación actual al periodo 2019. 


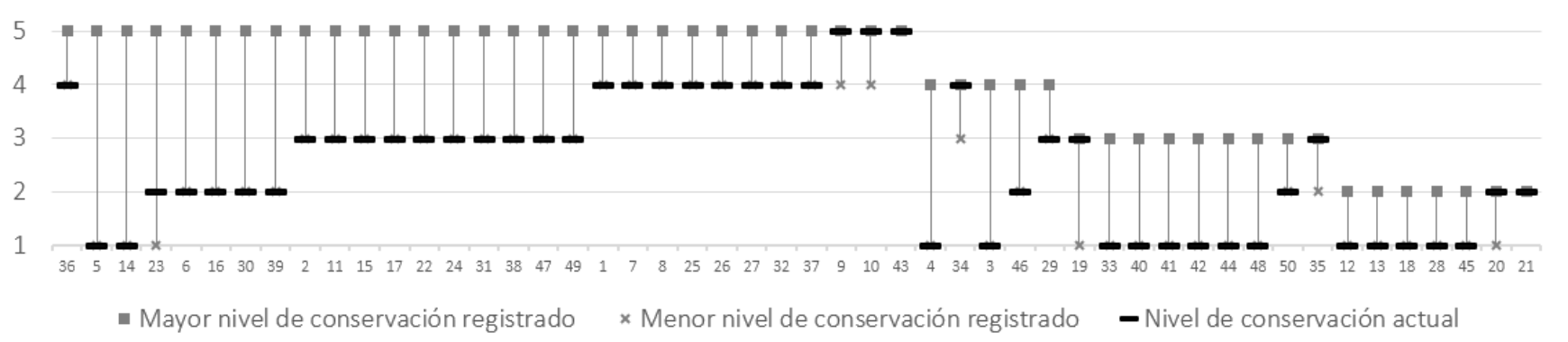

Figura 7. Evolución del nivel de conservación de las edificaciones de la AUM 15 de Junio. Fuente: Elaboración propia

Se distingue claramente una disminución del estado de conservación de las edificaciones. De las 29 edificaciones que alcanzaron una puntuación de 5 , solo 3 han logrado mantenerse en esta puntuación al 2019. De estas 29 edificaciones, 9 han reducido su nivel de conservación a 4 y 2 edificaciones han llegado a un nivel de conservación de 1. Las otras 21 edificaciones, presentan un patrón de evolución similar con 13 en un estado de conservación de 1. Sin embargo, de las 50 edificaciones revisadas poseían algún tipo de valor arquitectónico y su estado de conservación era muy bueno, entre 4 a 5 de puntuación, solo 10 conservan un tipo de conservación con una puntuación entre 3 a 4, considerándose entre regular a bueno, y solo 1 edificación mantiene una puntuación de 5 o muy bueno.

\section{Variables de la infraestructura urbana}

La aplicación de la prueba de regresión lineal jerárquica se realizó teniendo en cuenta la agrupación de las variables por las dimensiones planteadas. El algoritmo para su ejecución es el utilizado por la aplicación de software IBM SPSS v23.0.0.0. como una regresión lineal usando bloques para la agrupación de dimensiones.

Después de obtener los coeficientes de correlación para el modelo de regresión lineal jerárquico con todas las variables, se decidió retirar las variables: obstáculos verticales $u$ horizontales, presencia de arbolado y área verde, y uso diurno del espacio debido a que presentaron una significancia de $.357, \quad .358$ y .826 correspondientemente, por lo que se consideró que no eran estadísticamente significativas para la predicción del nivel de conservación en el caso del estudio del AUM 15 de Junio. A partir del modelo refinado, se consideran las variables mostradas en la Tablas 5, 6 y 7. Los indicadores descriptivos para las variables consideradas se muestran en la Tabla 5 y Figura 8. 


\section{Tabla 5}

Indicadores estadísticos descriptivos de las variables independientes

\begin{tabular}{|c|c|c|c|c|c|c|}
\hline Año & $\begin{array}{l}\text { Indicador } \\
\text { estadístico }\end{array}$ & Tamaño de la acera & Facilidad de cruce & $\begin{array}{c}\text { Uso nocturno del } \\
\text { espacio del espacio } \\
\text { público }\end{array}$ & Uso de edificación & $\begin{array}{l}\text { NC: Nivel de } \\
\text { conservación }\end{array}$ \\
\hline \multirow{3}{*}{1970} & Media & 2.04 & 2.94 & 2.36 & 4.06 & 4 \\
\hline & Mediana & 2 & 3 & 3 & 1 & 5 \\
\hline & Moda & 2 & 3 & 3 & 1 & 5 \\
\hline \multirow{3}{*}{1975} & Media & 2.34 & 2.98 & 3.42 & 1.42 & 4 \\
\hline & Mediana & 2 & 3 & 3 & 1 & 5 \\
\hline & Moda & 2 & 3 & 3 & 1 & 5 \\
\hline \multirow{3}{*}{1980} & Media & 2.36 & 2.94 & 3.42 & 1.4 & 3.98 \\
\hline & Mediana & 2 & 3 & 3 & 1 & 5 \\
\hline & Moda & 2 & 3 & 3 & 1 & 5 \\
\hline \multirow{3}{*}{1985} & Media & 1.76 & 2.92 & 3.24 & 1.4 & 3.84 \\
\hline & Mediana & 1.5 & 3 & 3 & 1 & 4 \\
\hline & Moda & 1 & 3 & 3 & 1 & 5 \\
\hline \multirow{3}{*}{1990} & Media & 1.76 & 2.92 & 3.22 & 1.4 & 3.6 \\
\hline & Mediana & 1.5 & 3 & 3 & 1 & 4 \\
\hline & Moda & 1 & 3 & 3 & 1 & 5 \\
\hline \multirow{3}{*}{1995} & Media & 1.72 & 3.14 & 3.2 & 1.38 & 3.3 \\
\hline & Mediana & 1 & 3.5 & 3 & 1 & 3 \\
\hline & Moda & 1 & 4 & 3 & 1 & 3 \\
\hline \multirow{3}{*}{2000} & Media & 1.72 & 3.14 & 3.2 & 1.38 & 2.98 \\
\hline & Mediana & 1 & 3.5 & 3 & 1 & 3 \\
\hline & Moda & 1 & 4 & 3 & 1 & 4 \\
\hline \multirow{3}{*}{2005} & Media & 1.72 & 2.86 & 3.2 & 1.38 & 2.8 \\
\hline & Mediana & 1 & 3 & 3 & 1 & 3 \\
\hline & Moda & 1 & 4 & 3 & 1 & 3 \\
\hline \multirow{3}{*}{2010} & Media & 1.72 & 2.84 & 3.08 & 1.38 & 2.54 \\
\hline & Mediana & 1 & 2 & 3 & 1 & 3 \\
\hline & Moda & 1 & 2 & 4 & 1 & 1 \\
\hline \multirow{3}{*}{2015} & Media & 1.74 & 2.72 & 3.08 & 1.38 & 2.52 \\
\hline & Mediana & 1 & 2.5 & 3 & 1 & 3 \\
\hline & Moda & 1 & 4 & 4 & 1 & 1 \\
\hline \multirow{3}{*}{2019} & Media & 1.74 & 2.72 & 3.08 & 1.38 & 2.54 \\
\hline & Mediana & 1 & 2.5 & 3 & 1 & 3 \\
\hline & Moda & 1 & 4 & 4 & 1 & 1 \\
\hline
\end{tabular}

Fuente: Elaboración propia 


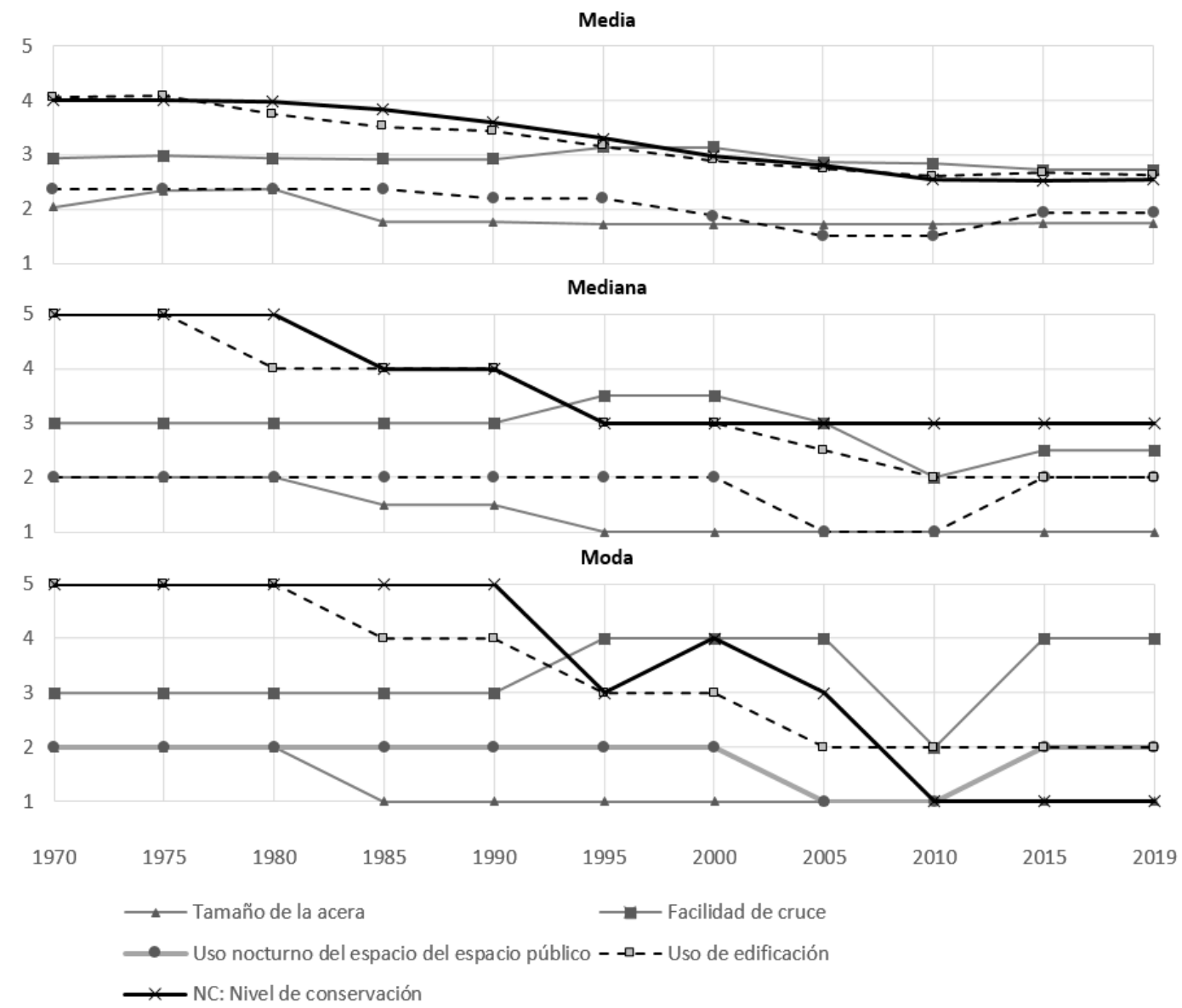

Figura 8. Evolución de las variables independientes de la infraestructura urbana. Fuente: Elaboración propia

Se resalta la similar conducta del uso de edificación, y la de uso nocturno del espacio público y el nivel de conservación, con una puntuación de 4.06 y 4 respectivamente en el año 1990, una puntuación de3.16 y 3.3 hacia el año 1995 y un valor de 2.62 y 2.54 hacia el año 2019. Por otro lado, la forma de la conducta del uso nocturno del espacio público es también similar, aunque con una puntuación menor. La mediana y la moda nos muestran un alarmante deterioro de las actividades nocturnas hacia el año 2005 en adelante con una puntuación de 1. La variable uso de edificación alcanza una puntuación de 5 hacia 1980 y una rápida caída hacia los 3 puntos en 1995 y 2 puntos en el 2005 cuyo estado se mantiene.

\section{Modelo de regresión lineal múltiple jerárquico}

Después de una nueva aplicación de la prueba, se obtuvieron los siguientes resultados de contribución de las variables a la predictibilidad del nivel de conservación, estos se muestran agrupados en la Tabla 6. 
Tabla 6

Valor $R$ del modelo de regresión

\begin{tabular}{|c|c|c|c|c|c|c|}
\hline Modelo & Predictores & $\mathbf{R}$ & $\mathbf{R}^{\mathbf{2}}$ & $\mathbf{R}^{2}$ Ajustado & $\begin{array}{c}\text { Error } \\
\text { Estándar }\end{array}$ & $\begin{array}{c}\text { Cambio en } \\
\mathbf{R}^{2}\end{array}$ \\
\hline 1 & Forma urbana & .079 & .075 & .075 & 1.327 & .079 \\
\hline 2 & Forma urbana, espacio público & .171 & .166 & .166 & 1.260 & .092 \\
\hline 3 & Forma urbana, espacio público, uso de la edificación & .594 & .591 & .591 & .882 & .423 \\
\hline
\end{tabular}

Fuente: Elaboración propia.

La Tabla 6 muestra los 3 modelos procesados, de los que se puede observar la predictibilidad del nivel de conservación es de un $7.9 \%$ considerando solo la forma urbana, de un $17.1 \%$ considerando la forma urbana y el espacio público y de un $59.4 \%$ considerando la forma urbana, el espacio público y el uso de la edificación. El mayor aporte a la predictibilidad se logra con la adición del uso de edificación, considerado a partir de su valoración por usos que promueven la caminabilidad, con $42.3 \%$.

Tabla 7

Coeficientes del modelo de regresión

\begin{tabular}{|c|c|c|c|c|c|c|}
\hline Modelo & Predictores & $\begin{array}{l}\text { Coeficiente no } \\
\text { estandarizado B }\end{array}$ & Error estadar & $\begin{array}{c}\text { Coeficiente } \\
\text { Estamdarizado } \\
\text { Beta }\end{array}$ & $\mathbf{t}$ & Significancia \\
\hline & (Constante) & 1.296 & .297 & & 4.369 & .000 \\
\hline \multirow[t]{4}{*}{1} & Tamaño de la acera & .396 & .077 & .231 & 5.128 & .000 \\
\hline & Facilidad de cruce & .426 & .068 & .280 & 6.222 & .000 \\
\hline & (Constante) & -.080 & .332 & & -.242 & .809 \\
\hline & Tamaño de la acera. & .395 & .073 & .230 & 5.374 & .000 \\
\hline \multirow[t]{4}{*}{2} & Facilidad de cruce & .377 & .065 & .248 & 5.771 & .000 \\
\hline & $\begin{array}{l}\text { Uso nocturno del espacio } \\
\text { público }\end{array}$ & .740 & .095 & .305 & 7.794 & .000 \\
\hline & (Constante) & -.235 & .233 & & -1.011 & .313 \\
\hline & Tamaño de la acera. & .175 & .052 & .102 & 3.357 & .001 \\
\hline \multirow[t]{3}{*}{3} & Facilidad de cruce & .128 & .047 & .084 & 2.724 & .007 \\
\hline & $\begin{array}{l}\text { Uso nocturno del espacio } \\
\text { público }\end{array}$ & .197 & .070 & .081 & 2.798 & .005 \\
\hline & Uso de edificación & .746 & .031 & .710 & 23.835 & .000 \\
\hline
\end{tabular}

En el modelo número 3, particularmente, la variable Tamaño de acera tiene una significancia de .001, la facilidad de cruce, una significancia de .007, el uso nocturno del espacio público una significancia de .005 y el uso de edificación una significancia menor a una milésima (.000). La constante presenta una significancia de .313, por lo que no se considerará en el modelo. Se debe resaltar que las variables poseen una escala de medición de igual rango y que el coeficiente Beta de la variable uso de edificación es notablemente mayor con un valor de .710 , seguido del tamaño de la acera con .102. 
Aunque es recomendable usar la mayor predictibilidad, se presentarán el modelo 2 y 3 como y2 y $y_{3}$. La formulación del modelo de regresión simple considerará las dimensiones correspondientes:

$$
\begin{gathered}
y_{2}=.230 x_{1}+.248 x_{2}+.305 x_{3}+\varepsilon \\
y_{3}=.102 x_{1}+.084 x_{2}+.081 x_{3}+.710 x_{4}+\varepsilon
\end{gathered}
$$

\section{Discusión de Resultados}

La situación del AUM 15 de Junio se alinea a lo que concluye Gallego (2016), de que, una pobre gestión urbana tiene implicaciones sociales negativas, y que se requieren de políticas más flexibles. Además de instrumentos dinámicos y efectivos para la planificación y gobernanza que incorporen la forma urbana, el espacio público y el uso de la edificación en el AUM 15 de Junio.

Una solución común en la ciudad de Huancayo frente al incremento del tránsito vehicular o la distribución de bienes en zonas comerciales es la modificación de la sección de vía. Córdova, Merchán y Torres (2014) indican que análisis de redes de distribución pueden generar planes de distribución mas precisos y pueden modelarse bajo diversas restricciones. Estos modelos resaltan ideales para zonas comprometidas con el patrimonio y no requieren modificar la sección de la vía.

Así como Lavrov, Perov, y Eremeeva (2018, p.419) enfatizan la importantcia de las vias peatonales en áreas de valor histórico, es evidente la reducción de espacios que permian el transito peatonal fluido entre los extremos del AUM en estudio, interfiriendo notablemente con su dinámica urbana y posiblidades de uso.

En el caso del AUM 15 de Junio, tal como manifiesta Rojas (2010b) se distingue una posible desvinculación de las personas con el sitio. En el caso de estudio se resalta la disminución de la capacidad de gestión con el propietario después de los años 1995. Durante este periodo muchos de los dueños de las casas abandonan las mismas por razones diversas o las propiedades son heredadas a familiares o servidores domésticos que convivieron con los dueños durante casi toda su vida. Estos eventos generarían conflictos internos sobre la posesión legal de los bienes que causarían juicios o divisiones informales de las edificaciones y podrían haber causado la afectación posterior de los inmuebles.
A pesar del valor histórico y cultural del AUM 15 de Junio, es claro distinguir la existenia de una brecha entre la cultura local y la planificación urbana. Dinardi (2015) supone que la cultura es ambigua y enfatiza que es muy dificil replicar un modelo de políticas solo basadas en la cultura. Para Zhang, Lu y Song (2012) las iniciativas de renovación urbana deben considerar metas integrales en un proceso de implementación adaptable y colaborativo.

Elshater (2013) considera qe los ambientes urbanos deben alcanzar un entorno habitable adecuado para el residente y los visitantes del lugar. Esta perpectiva es en particular importante cuando nos refereimos a espacios que agrupan características culturales. Lavrov, Perov, y Eremeeva (2018, p.421) también señalan que las condiciones ambientales pueden ser un factor negativo importante. Sin embargo, durante el periodo 1970 a 1990 en el que se utilizaría la zona como paradero informal sin ser determinante en la decisión de modificar las propiedades pero siendo quizas un motivo para la migración de los residentes mayores, en este sentido se requieren mayores estudios.

Aunque Mària y Salvadó (2017, p.30) indican que, en entornos urbanos con gran riqueza patrimonial, la conservación de zonas históricas involucra el estudio del paisaje urbano en el entorno. La ZUM de Huancayo no fue evaluada en estos términos y muchas construcciones nuevas de forma dispersa alteran el paisaje urbano. Muchas de estas intervenciones son visibles en el AUM 15 de Junio y los bajos niveles de conservación actuales. Por otro lado, Almandoz (2006) sugiere la importancia de los estudios de articulación social y el rol de los barrios y comunidades para comprender su situación actual. El AUM en estudio tiene una dinámica fuertemente vinculada al desarrollo comercial y los vínculos legales de tenencia de la propiedad.

\section{Conclusiones}

Las intervenciones a los centros históricos examinados por Rojas y Lanzafame (2011) en ciudades latinoamericanas, presentan usos activos mixtos en las áreas históricas y cuyos servicios son financiados por los residentes e inversionistas que explotan el valor del patrimonio. En el caso del AUM en estudio, los propietarios nunca han sido asesorados y solo perciben el beneficio inmediato a través del alquiler, venta o un negocio rentable similar al de los establecimientos cercanos. Inclusive, las edificaciones en 
estas zonas son propensas a sufrir alteraciones o a ser demolidas debido a intereses particulares de sus propietarios, autoridades o debido al deterioro por causas ambientales.

La investigación revela que la forma urbana, el espacio público y el uso de la edificación son predictores efectivos para conocer el nivel de conservación, siendo este último el de mayor representatividad en el caso del AUM 15 de Junio. Los indicadores estadísticamente mas significativos para la predicción del nivel de conservación es el tamaño de la acerca, la facilidad de cruce, el uso de nocturno del espacio público y el uso de la edificación.

Adicionalmente, para, Ortiz de Villajos Carrera (2015, p.453-460) el valor cultural del patrimonio requiere ser transmitido para que se integre a la tradición para que no caiga en olvido y se convierta en ruina. El contexto urbano desde 1980 del AUM 15 de Junio muestra la necesidad de propuestas de desarrollo del sector y el requerimiento de investigaciones orientadas a la planificación inclusiva que enlace los planes urbanos y la preservación de ambientes urbanos patrimoniales como el AUM 15 de Junio. Mària y Salvadó (2017, p.34) resaltan el reuso adaptado de edificaciones para satisfacer diversas necesidades de ocupación como una alternativa para su conservación y preservación. En el AUM 15 de Junio se han encontrado edificaciones cuyas fachadas pueden ser rehabilitadas. Además, existen espacios disponibles para el diseño y ejecución de proyectos que favorezcan al paisaje urbano, ya que son espacios altamente derruidos o lotes vacios.

Suarez (2012) aplica la idea de patrimonio de las edificaciones no solo a su autenticidad arquitectónica, sino también a su capacidad de ser escenarios culturales populares. Las áreas urbanas conexas al AUM 15 de Junio se encuentran desarticuladas espacialmente. Los planes urbanos de la ciudad de Huancayo no consideraron el valor cultural de la zona centro de la ciudad en gestiones previas y solo se especulaba la delimitación del ZUM, esto ayudo a flexibilizar las decisiones sobre proyectos de construcción obviando la variable cultura. Para Hwang
(2014) la regeneración urbana esta basada en el atributo cultural. Como otras ciudades peruanas, la ciudad de Huancayo durante repetidos periodos de gestión municipal ha priorizado el flujo de tráfico vehicular como benéfico para los residentes y una solución directa ante el crecimiento de la población urbana. Es necesario recordar que enfatizan que la evaluación de la calidad de habitabilidad no solo requiere de la disponibilidad de acceso al trasnporte vehicular, sino que a un manejo adecuado del tráfico se debe sumar la inserción de medios peatonales (Lavrov, Perov y Eremeeva, 2018).

Entre las principales causas del deterioro del AUM 15 de Junio, resalta la posesión legal junto a acciones de división de los lotes y el ínteres de explotación económico bien inmueble sin considerar su valor histórico. Además, la mala gestión urbana del AUM 15 de Junio ha perjudicado la conservación del este espacio. Se identifico una carencia de desarrollo de investigaciones e inclusión de los actores en los procesos de planificación.

Tal como Suarez (2012) y Mertins (2018) afirman que los centros históricos y sus alrededores en ciudades latinoamericanas son un factor de imagen efectivo para la ciudad. El AUM 15 de Junio pasa por esta situación de deterioro físico y de usos inadecuados en las zonas circundantes. Versaci (2016) muestra que es de vital importancia incluir reformas de legislativas para el anexo y articulación de espacios urbanos históricos en las ciudades y que estas acciones contribuyen al desarrollo sostenible de las ciudades. En la última década, mayores movimientos comerciales en los alrededores y el crecimiento poblacional incentivan la ampliación de niveles de edificación. En el caso de estudio, las debilidades en las regulaciones sobre el patrimonio no permiten el desarrollo de acciones para su conservación.

EI AUM 15 de Junio se encuentra en un estado precario de conservación y de no desarrollarse medidas para su conservación o adecuación, los inmuebles con valor patrimonial se extinguiran en poco tiempo [R 


\section{Referencias}

Acierno, M., Cursi, S., Simeone, D., \& Fiorani, D. (2017). Architectural heritage knowledge modelling: An ontology-based framework for conservation process. Journal of Cultural Heritage, 24, 124-133. https://doi.org/10.1016/j.culher.2016.09.010

Almandoz, A. (2006). Urban planning and historiography in Latin America. Progress in Planning, 65, 81-123. https://doi.org/10.1016/j.progress.2006.02.002

Barros, A., Martinez, L. y Viegas, J. (2017). How urban form promotes walkability? Transportation Research Procedia, 27, 133-140. https://doi.org/10.1016/j.trpro.2017.12.039

Cheng, Y., Dang, A. y Peng, X. (2014). Building a Cultural Heritage Corridor Based on Geodesign Theory and Methodology. Journal of Urban Managemen, 3(1-2), 97-112. https://doi.org/10.1016/S22265856(18)30086-4

Concha, A. y Concha, Á. (2014). Interpretación arquitectónica de las tipologías patrimonio cultural del eje vial de la avenida Giraldez de Huancayo. ArquiTextual, 3(3), 6-16.

Córdova, J., Merchán, D. y Torres, S. (2014). Redesigning a Retail Distribution Network in Restricted Urban Areas: A Case Study on Beverage Distribution in the Historic Center of Quito. Journal of applied research and technology, 12(5), 850-859. Recuperado de http://www.scielo.org.mx/scielo.php?script=sci artte xt\&pid=S1665-64232014000500003\&lng=es\&tlng=en

Dinardi, C. (2015). Unsettling the role of culture as panacea: The politics of culture-led urban regeneration in Buenos Aires. City, Culture and Society, 6, 9-18. https://doi.org/10.1016/j.ccs.2015.03.003

Elshater, A. (2013). Urban Reloading Philosophy Adequate to People-Place. Procedia - Social and Behavioral Sciences, 101, 526-541. https://doi.org/10.1016/i.sbspro.2013.07.226

Esquivel-Cuevas, M., Hernández-Mercado, O., \& GarnicaMonroy, R. (2013). Modelo de Accesibilidad: Modelo de Accesibilidad. Bitacora Urbano Territorial, 23(2), 21-41.

Gallego, C. (2016). Urban Renewal Versus Rehabilitation Case of Fuencarral Social Housing Estates in Madrid. Procedia Engineering, 161, 2109-2114.
Guerín, F. (2018). Las dimensiones socioantropológicas, políticas y urbanísticas del noctambulismo en París y Madrid. En R. Serrano, Movilidad Urbana y Espácio Público: Reflexiones, métodos y contexto (págs. 5892). Bogotá: Dirección de Investigación - Universidad Piloto de Colombia.

Hwang, K. (2014). Finding Urban Identity through Culture-led Urban Regeneration. Journal of Urban Management 2014, Vol. 3, No. 1-2, pages 67-85, 3(1-2), 67-85. https://doi.org/10.1016/S22265856(18)30084-0

INEI (2018). Perú: Perfil Socio Demográfico: Informe Nacional Censos Nacionales 2017: XII de Población, VII de Vivienday III de Comunidades Indígenas. Lima: Instituto Nacional de Estadística e Informática.

Obtenido de https://www.inei.gob.pe/media/MenuRecursivo/publ icaciones digitales/Est/Lib1539/

Lavrov, L., Perov, F., \& Eremeeva, A. (2018). Methods of the development of pedestrian traffic routes in the historical center of Saint Petersburg. Transportation Research Procedia, 36, 418-426.

Mària, M. y Salvadó, N. (2017). Conservation of the urban heritage and sustainability: Barcelona as a paradigm. Energy Procedia, 115, 29-40. https://doi.org/10.1016/i.egypro.2017.05.004

Mertins, G. (2018). El patrimonio urbano como valor creciente para la imagen y la gestión de las ciudades. Memorias: Revista digital de Historia y Arqueología desde el Caribe colombiano, 18, 160-167. Obtenido de http://rcientificas.uninorte.edu.co/index.php/memori as/article/view/4876/2962

Ministerio de Cultura (2016). Marco Legal de Protección del Patrimonio Cultural. Lima: Dirección General de Defensa del Patrimonio Cultural - Ministerio de Cultura. Obtenido de http://www.cultura.gob.pe/sites/default/files/archivo sadjuntos/2016/08/marcolegalokversiondigital.pdf

Ortiz de Villajos Carrera, J. (2015). La construcción patrimonial en la ciudad intermedia. Málaga, retratos patrimoniales no pronosticados en derivas urbanas programadas del tiempo presente (Tesis Doctoral). Universidad de Sevilla. 
Rafiemanzelata, R. y Emadib, M. I. (2017). City sustainability: the influence of walkability on built environments. Transportation Research Procedia, 24, 97-104. https://doi.org/10.1016/i.trpro.2017.05.074

Raja, R. y Zaharib, R. (2013). Perceptions of the Urban Walking Environments. Procedia - Social and Behavioral Sciences, 105, 589-597. https://doi.org/10.1016/j.sbspro.2013.11.062

Rojas, E. (2010a). Neighbourhood Upgrading Programmes: Lessons from Latin America and the Caribbean. En E. Rojas, Building Cities: Neighbourhood Upgrading and Urban Quality of Life (págs. 137-176). Washington: Inter-American Development Bank.

Rojas, E. (2010b). Preventing New Informality. En E. Rojas, Building Cities: Neighbourhood Upgrading and Urban Quality of Life (págs. 101-135). Washington: Inter-American Development Bank.

Rojas, E. y Lanzafame, F. (2011). City Development: Experiences In The Preservation Of Ten World Heritage Sites. Washington: Inter-American Development Bank.

Roussel, J. (2018). La noción de comodidad al caminar en el espacio público parisino. En R. Serrano, Movilidad Urbana y Espácio Público: Reflexiones, métodos y contexto (págs. 128-150). Bogotá: Dirección de Investigación - Universidad Piloto de Colombia.

Samadi, Z. y Mohd, R. (2012). Physical and Spiritual Attributes of Urban Heritage Street's. Procedia Social and Behavioral Sciences, 36, 342-349. https://doi.org/10.1016/j.sbspro.2012.03.038

Sánchez, A., Teutli, M. y Maximiliano, H. (2016). Where are Going to Definitions Historical Centers in Latinoamerican? Territory, City and Heritage. Procedia - Social and Behavioral Sciences, 225, 27-33.
Serag, H., Shalaby, A., Elsayed, H., \& Elariane, S. (2013). Principles of urban quality of life for a neighborhood. HBRC Journal, 9, 86-92. https://doi.org/10.1016/j.hbrcj.2013.02.007

Singh, R. (2016). Factors affecting walkability of neighborhoods. Procedia - Social and Behavioral Sciences, 216, 643-654. https://doi.org/10.1016/j.sbspro.2015.12.048

Suarez, R. (2012). ¿Barrio Abajo tiene valor patrimonial o sólo es un barrio residencial? Memorias: Revista digital de Historia y Arqueología desde el Caribe colombiano, 18, 238-257. Recuperado de http://rcientificas.uninorte.edu.co/index.php/memori as/article/view/4702/2983

Versaci, A. (2016). The Evolution of Urban Heritage Concept in France, Between Conservation and Rehabilitation Programs. Procedia - Social and Behavioral Sciences, 225, 3-14. https://doi.org/10.1016/j.sbspro.2016.06.003

Yoshii, Y. (2016). Preserving Alleyways to Increase Walkability of Historical Japanese Cities. Procedia Social and Behavioral Sciences, 216, 603-609. https://doi.org/10.1016/j.sbspro.2015.12.034

Zhang, C., Lu, B. y Song, Y. (2012). Involving the Community in Inner City Renewal: A Case Study of Nanluogu in Beijing. Journal of Urban Management, 1(2), 53-71. https://doi.org/10.1016/S2226$\underline{5856(18) 30060-8}$ 